\title{
The Implication of Visual Media in Foreign Language Teaching and Learning: Take Chinese as an Example*
}

\author{
ZHOU Wen-hua \\ Nanjing Normal University, Nanjing, China
}

\begin{abstract}
Visual media, such as TV series and film, can play an important role in foreign language teaching and learning because of their unique advantages in audio-visual facets: They can provide a meaningful context of language input and help learners understand the usage of the language; they are conducive to cultivating learners' language skills, communicative competence, and cultural understanding; they can also help to maintain learners' interest in learning and expand Chinese learning to communities. The study shows that visual media can be designed and used to bring communication, cultures, connections, comparisons, and communities into language classes.
\end{abstract}

Keywords: visual media, authentic context, language input, language competence, culture

\section{Introduction}

In recent years, more and more people around the world are trying to learn Chinese as Foreign Language (CFL). Learning CFL has developed quickly overseas in recent years. Nowadays, Mandarin Chinese has become one of the fastest growing foreign languages in the United States, according to the American Council on the Teaching of Foreign Languages (ACTFL). The ACTFL's 2017 Annual Report shows that Chinese is now the third of top three languages represented by the attendees and has $12 \%$ of attendees.

Following the five C's standards, Teaching Chinese as a Foreign Language (TCFL) will not only focus on the Chinese language acquisition, but also on introducing Chinese culture to learners and developing diverse communication strategies. Like all foreign language teaching, the ultimate goal of TCFL is to cultivate learners' Chinese language audible comprehension, speaking, reading, writing, and other communicative capabilities. In terms of comprehensively cultivating learners' Chinese language, especially in regards to listening comprehension and speaking, visual media have a unique advantage; Studies (e.g., Snyder \& Colón, 1988; Reid, 1995; ZHANG, 1995; Kao \& O’Neill, 1998; Gilakjani, 2012) have shown that visual and auditory methods used in language learning would help to cement what has been learned in the learner's memory and would be remembered longer. Films are also widely used as "cultural text" to assist learners in their understanding of customs in a visual way (KONG, 2011). ZHANG (2013) also observed a group of secondary-school learners of Chinese and stated that "the integration of film into language study can indeed impact learner's understanding of Chinese culture" (p. 13).

\footnotetext{
* Acknowledgements: This research was supported by Chinese National Social Science Grants 17BYY117.

ZHOU Wen-hua, associate professor, Ph.D., International College for Chinese Studies, Nanjing Normal University, Nanjing, China.
} 


\section{LEARNING: TAKE CHINESE AS AN EXAMPLE}

\section{The Great Role of Visual Media in Foreign Language Teaching and Learning}

\section{Cultivating Learners' Language Skills}

In addition to the exciting plots, an excellent film or TV series must have precise and normative language which is worth learning. This provides an optimal chance of Chinese language learning for learners. As it is well known, language learning is a gradual and complicated process, which involves vocabulary, phrases, sentences, textual expression, and many other aspects.

Take vocabulary teaching and learning as an example, most vocabulary will have more than one meaning and usage, and these meanings and usages will appear in different contexts. Last century, scholars noticed that TV series and film played an important role in second language vocabulary learning (cf. Cho \& Krashen, 1994; Webb \& Chang, 2014). Shabani and Marjan (2015) have also explained the impact of watching captioned TV series and films on vocabulary development in EFL (English as a Foreign Language) learners as well as the CFL learners. The cognitive habits of foreign learners are different from those of the Chinese, and the differences between their mother tongues and Chinese may cause obstacles in Chinese learning and cultural understanding. It is difficult for learners to understand and speculate on the use of Chinese vocabulary by meanings. Sometimes even if they remember the meaning of the words, they may not know how to use them in the proper context. In foreign language teaching, teachers often encounter a situation in which learners remember the vocabulary, but are unable to produce properly formatted sentences. They learn and are able to use single phrase sentences, but cannot formulate a dialogue. Therefore, in the teaching of Chinese as a foreign language, it is vital to not only explain the meaning of words, but also to explain the cultural usage of words and the context in which they appear. Teaching the vocabulary in the sentence, with dialogue and other context, is the most effective method. TV series and films can provide a rich context to the Chinese vocabulary learning: from the sentence phrases to the dialogue and even the situation in which to use certain phrases. In this way, foreign learners will be able to understand the context of conversations and when to use the proper vocabulary. Phrases, sentences, and relative expression learning is the same. In short, the use of TV series and films can make TCFL a comprehensive and well-rounded experience.

In films and TV series, due to the need for the development of the plot, there are many words that learners initially do not have to learn. Because of this, the vocabulary in TV series and films may be more difficult than in the vocabulary being taught in the textbooks. In other words, there will be a lot of vocabulary words that do not appear in the syllabus or textbooks. For the Chinese language learning, especially in the initial stages, we need to teach learners basic vocabularies and grammar from the easiest grammar points to the more difficult points; for the intermediate and later stage, especially the advanced stage of language learning, learners should be able to learn and understand every word which appears in films and TV series. Each of the TV series or films has a storyline and the actors' performances which will give learners cues to understand the language in the story, similar to the role gestures play in second language learning (e.g., LIU, 2002; Sueyoshi \& Hardison, 2005; Morett, Gibbs, \& MacWhinney, 2012). However, TV series or films will provide more cues than the gestures in the classroom. For example, in the HOME WITH KIDS, there are a lot of Beijing dialect characteristics in the vocabulary used, like "Dăochi” which means "makeup or decorate", "Biéjiè" which means "stop sb. to do sth, et cetera". These words are impossible to record in the textbooks or even in people's conversations in other cities in China. With the help of the context of the films or TV series and the actor's performance, it is easier for learners to understand the meaning of these dialect words. According to our study, 
the unique dialect characteristics of these vocabularies may pique the learners' curiosity, and learners may learn them even faster than other words in the end.

Another important point is that the TV series and films can have subtitles, which provides learners with the opportunity to watch while listening. In foreign countries, video subtitles have been developed and used by educational researchers and language educators as an important teaching resource and tool (e.g., DAI, 2005; Kovacs \& Miller, 2014; Ayand \& Shafiee, 2016). Through subtitles, learners can achieve the ideal state of language audiovisual learning, and some high-level learners can even study the foreign language through watching subtitled TV series or films independently outside of class. Changing TV series or films into a living teaching material is not impossible. For example, in recent years "watching the US TV series, and learning English" has occurred around the world. We believe that if we continue working on the application of Chinese TV series and films in CFL teaching and learning, in the near future it may lead to a trend "to watch the Chinese TV series, and to learn Chinese" around the world, and even other languages.

\section{Cultivating Learners' Communicative Competence}

Chinese TV series or films show authentic scenes of interactions between Chinese people, but do not show virtual teaching scenes. Such films as HOME WITH KIDS and A LOVE FOR SEPARATION show the Chinese family life episodes related to the education received in the classroom setting. Learners can have an immersive experience while watching a TV series or films. The language of the TV series or films is more relatable to language used in everyday life than the language used in teaching materials such as textbooks. TV series and films are also more interactive and conducive to cultivating learners' practical application of the Chinese language.

Learning the language through TV series or films can really encourage learners' understanding of the different expressions used in the Chinese language and the context in which to use them. For example, the use of Chinese idioms and slangs in Chinese is very difficult for foreign learners to understand. Even if they have learned some idioms or slangs, they can not necessarily use them in the right situation. For example, when a foreign learner heard a Chinese friend complimented his Chinese speaking, the foreign learner said, "Nì pāiwǒmăpi". This idiom expresses "you are flattering me" rather than the appropriate "you are overstating me". He used this idiom in the wrong situation. Another example is when the learner described the teacher's students as "Lăoshīde xuésheng wúkǒngbùrù" which means "the bad things will go to everywhere they can reach", when in actuality, he wants to express that his teacher has students at every corner of the world. Again, this was not a properly used or spoken idiom. Through TV series, learners can understand the context of relevant idioms used to help to understand and master the relevant usage, so as to help learners improve their ability to communicate in real, everyday life. For example, in HOME WITH KIDS, "Xiăo Yǔ" (one character in the play) often uses the new word "Dōngdōng" which is used by the young generation in China instead of the common word "Dōngxi". Despite the differences in these two words, with the context of the film and the actor's performance, most learners are able to understand the meaning of the vocabulary fairly well. Additionally, learning new words, such as "Dōngdōng" which is commonly used among the young generation, often helps foreign learners to communicate with young people in China with practical and current communication. Another example is the modal words, which are usually the most difficult word class for foreign learners to learn and use. In HOME WITH KIDS, the modal word "Ah/ā" which appeared at the end of the sentence has different communication function usages, combined with the scenes learners can naturally understand and 
master the different function usages of the modal word "Ah/ā" and use it in the authentic communication (SUN, 2013). This is much more effective than a different communicative function in the classroom.

In addition, the TV series or films can also provide learners with different sentence patterns and contexts. If, in the classroom, teachers need to design a large number of examples and exercises to teach and practice these sentences, and learners may still not be able to use these sentences in daily conversations. But for TV series or films, learners can watch the performance while learning the language and the key point is that they understand the sentences in the context, which can be used in daily communication. Learners imitate the use of these sentences in the TV series or films, so as to improve their practical ability of communication. At the same time, learners can also make a role play to recap and practice the scenes in the TV series or films to imitate the language usage in the classroom. This is much more interesting than the artificial dialogue practiced in the classroom and more closely related to daily conversation. The TV series or film scenes imitated and practiced can not only achieve the practice of the common language training, but also improve the learner's actual communication ability.

\section{Cultivating Learners' Culture Understanding}

TV series or film is an important means of dissemination of culture. No matter what period the TV series or film belongs to, they can reflect the daily life of Chinese people and show the natural culture, with a strong sense of the times. HOME WITH KIDS shows the Chinese lifestyle. GROWING PAINS and A LOVE FOR SEPARATION reflect the background of the Chinese family, education, and a life with current everyday challenges. I LOVE MY FAMILY is the traditional Chinese family and shows the dynamic of the relationships between the residents of the neighborhood. CHINESE STYLE DIVORCE, ROMANCE OF OUR PARENTS, and others display the traditional Chinese marriage notions from decades ago. These TV series and films contain a lot of pieces of Chinese cultural elements, such as China's "collectivism and individualism", "love and marriage", Chinese-style greetings and expressing gratitude, traditional Chinese rituals, and so on. These "concepts, behaviors, and things that relate to the story of Chinese culture, help learners gain a deeper understanding of Chinese culture" (LIU \& DENG, 2009).

While watching the TV series and films, learners will naturally contrast the culture embodied in the TV series and films with the culture of their countries. If it is totally different from the culture in their country, learners will perceive and understand it as a new Chinese culture. They can also find the differences between the two cultures by comparison, so as to deepen the understanding of Chinese culture. Through the TV series and films, foreign learners can naturally perceive and understand the relevant Chinese culture. This subtle show of culture is the most effective way to help the learner understand other countries' culture.

\section{Maintaining the learners' Interest in Learning}

The interests are the key to the success of all learning and achievement. As we all know, language learning is a relatively boring process. The foreign learners are quick to lose their interest in learning. If there is no clear purpose and strong motivation to learn, learners can easily become tired with the simple language classes. Even some learners who are interested in Chinese at the beginning, if they always learn the virtual text in the classroom and the traditional teaching methods and means do not change with the changing of the times, the topic cannot hold learners' interest for long. Meanwhile, these visual media can play a certain role in keeping the learners' language learning interest, and it is a good way for flipping language classroom (Fethi \& Marshall, 2017). 
On the one hand, the story and actors' performance of TV series or films may attract the learners and give learners the feeling of immersion and entertainment, so that learners are in a pleasant mood to learn the language and thus continue to be interested in the language learning process. The practice has proven that language learning can be also accomplished in a subtle and far more interesting way than through textbooks. The learner can learn much more and sometimes even achieve a multiplying effect.

On the other hand, the era of TV series and films can present the real lives of different social groups during different time periods. This enables learners to understand the traditional communication and Chinese culture through the TV series or films, which is an important aspect to attract many foreign learners. Through the teaching of the Chinese in the United States, it has been observed that learners are very fond of learning a second language in the form of watching TV series or films. They generally believe that the textbooks are always lacking for real themes of the present day. They are more willing to see the real life in China. TV series and films are important means of their exposure to authentic Chinese interactions. Through TV series and films, they understand the real life and culture of China while improving their practical ability to communicate, which encourages a strong and maintained interest in Chinese language learning.

In short, Chinese teaching experiences in the U.S. proved that the use of TV series or films in Chinese language teaching and learning is very popular with learners and helps them to maintain a strong interest in their Chinese language learning. We will show our empirical study in the next section.

\section{Expanding Foreign Language Learning to Communities}

In addition to the above points, the TV series and films also have the advantage of reaching "beyond time and space, direct fast, broad audience" (HUANG, 2013, p. 122). These features provide a broader space for Chinese TV series and films, as it allows foreign learners of different communities to learn Chinese and understand Chinese culture without going to the classroom. This has two advantages: First, learners can break the constraints of time and space through the TV series or films to expand classroom learning, either to review the contents they have learned in the classroom or to learn new knowledge and culture by themselves outside of the classroom; second, different communities around the world that are interested in Chinese language and culture can learn Chinese language and Chinese culture through Chinese TV series or films without the formal classroom setting at any time and at any place.

In other words, Chinese TV series or films will play a certain role in promoting the Chinese learning in communities around the world. Then showing how to use them in CFL teaching and learning is another important research topic that we will focus on in the following research.

\section{Conclusion}

The current study suggests that (1) the authentic context from the visual media provides authentic language input and can be used as classroom conversations; (2) scenes from target language countries present culture variety, which ranges from classical to pop culture; and (2) learners build connections between textbooks and the language used in visual media. Through cultural comparisons, learners gain a deeper understanding of the cultural value of Chinese society. Thus, while sharing their observations with the community, they are able to self-reflect and be open-minded about the cultural differences. Learning is a lifelong process, one film or TV series certainly cannot enhance learners' language proficiency. However, the cultural influences will take their learning journey a long way. 


\section{LEARNING: TAKE CHINESE AS AN EXAMPLE}

The important role of visual media in CFL teaching and learning is obvious, but how to use it effectively in the CFL teaching is another important issue. In other words, how to combine visual media with traditional Chinese teaching is worthy of further study. We should start from two facets: (1) Chinese film and television producers should produce plenty of TV series or films with the different themes to reflect the real life of China and cultural facts. These excellent TV series or films will provide a large number of language expression norms for the CFL teaching and learning; and (2) the teachers of CFL must strengthen the application of TV series and films in CFL teaching, select the film and television works that will be conducive to Chinese teaching and cultural understanding for different levels of learners, and find more effective and creative ways of combining visual media with daily Chinese teaching.

\section{References}

Ayand, F. K., \& Shafiee, S. (2016). Effects of English and Persian subtitles on oral fluency and accuracy of intermediate Iranian EFL learners. International Journal of Applied Linguistics and English Literature, 5(3), 133-144.

Cho, K. S., \& Krashen, S. D. (1994). Acquisition of vocabulary from the Sweet Valley Kids series: Adult ESL acquisition. Journal of Reading, 37(8), 662-667.

DAI, J. (2005). Film and television subtitles and foreign language teaching. Technology Enhanced Foreign Language Education, 3, 18-22.

Fethi, K., \& Marshall, H. W. (2017). Flipping movies for dynamic engagement. In J. Mehring and L. Adrian (Eds.), Innovations in flipping the language classroom: Theories and practices. New York, NY: Springer.

Gilakjani, A. P. (2012). Visual, auditory, kinaesthetic learning styles and their impacts on English language teaching. Journal of Studies in Education, 2(1), 104-113.

HUANG, J. (2013). International Chinese teaching based on TV media. Journal of Hubei Radio \& Television University, 12, 120-121.

Kao, S. M., \& O’Neill, C. (1998). Words into worlds: Learning a second language through process TV series. USA: Greenwood Publishing Group.

KONG, H. (2011). Reflections on teaching Chinese language films at American colleges. Asianetwork Exchange, 18(2), 13-29.

Kovacs, G., \& Miller, R. C. (2014). Smart subtitles for vocabulary learning. Proceedings of the SIGCHI Conference on Human Factors in Computing Systems, ACM, New York, USA.

LIU, J. (2002). Process TV series in second and foreign language classrooms. In G. Bräuer (Ed.), Body and language: Intercultural learning through TV series (pp. 51-70). Greenwood Publishing Group.

LIU, L., \& DENG, F. (2009). Chinese audio-visual tutorials—Home With Kids. Beijing: World Book Publishing Company.

Morett, L., Gibbs, R., \& MacWhinney, B. (2012). The role of gesture in second language learning: Communication, acquisition, \& retention (pp. 773-778). Proceedings of the Annual Meeting of the Cognitive Science Society.

Reid, J. M. (Ed). (1995). Learning styles in the ESL/EFL classroom. Boston, MA: Heinle \& Heinle Publishers.

Shabani, K., \& Marjan, P. Z. (2015). The impact of watching captioned TV series on vocabulary development of EFL students. Journal for the Study of English Linguistics, 3(1), 118-129.

Snyder, H. R., \& Colón, I. (1988), Foreign language acquisition and audio-visual aids. Foreign Language Annals, 21, $343-348$.

Sueyoshi, A., \& Hardison, D. M. (2005). The role of gestures and facial cues in second language listening comprehension. Language Learning, 55(4), 661-699.

SUN, Y. (2013). An analysis of the communicative functions of "Ah" at the end of a sentence: A case study of "Home with Kids". Language Teaching and Linguistic Studies, 3, 99-105.

Webb, S., \& CHANG, A. C. S. (2014). Second language vocabulary learning through extensive reading with audio support: How do frequency and distribution of occurrence affect learning? Language Teaching Research, 19(6), 667-686.

ZHANG, D. (1995). The principle and design of TV Chinese teaching TV series. Language Teaching and Linguistic Studies, 3 , 106-114.

ZHANG, Q. (2013). The impact of film and film-based activities on the attitudes of English-speaking secondary-school students towards L2 Chinese. Journal of Creative Practices in Language Learning and Teaching, 1(2), 1-17. 